\title{
Selected patent applications in carbohydrate sequencing
}

\author{
Patent \# Subject \\ WO 9639417 Performing chemical, biochemical, or biological reactions \\ by trapping a particle in an optical trap and moving it \\ through various reagents in regions of thin film; useful \\ in the synthesis and sequencing of oligonucleotides, \\ peptides, and carbohydrates. \\ WO 9636986 Sequencing polymers such as DNA, RNA, peptide \\ nucleic acids, proteins, peptides, and carbohydrates \\ by obtaining mass-to-charge ratios of polymer fragments, \\ preferably by using a mass spectrometer, and performing \\ statistical analysis.
}

WO 9636872 Multiplexed capillary electrophoresis system, used in detection of sample species. Has an array of coplanar parallel capillaries, each having an annular wall with first transparent portion defining transparent path, and coherent light source; can be used for the analysis of proteins, polypeptides, saccharides and polysaccharides, nucleic acids and oligonucleotides, polynucleotides, carbohydrates, cellular material, and pharmaceuticals, for applications such as DNA sequencing, fragment analysis, and fingerprinting.

US 5569366 Electrophoretic analysis of mono- and/or polysaccharide compounds by capillary electrophoresis of fluorescent-labeled derivatives, argon laser excitation and monitoring fluorescence, giving very low detection limit; applications include carbohydrate and glycoprotein sequencing, industrial sugar and carbohydrate analysis, drug analysis, and diagnosis.

EP 732584 Sequencing of nucleic acids, proteins, or carbohydrates using near-field probe technique to generate a super-resolution chemical analysis of a portion of the molecule, and correlating chemical analysis with a broad spectral content of a referent molecule for generating a code sequencing of the portion of the molecule, which can generate large sequences or a whole genome in reduced time.

WO 9533989 Apparatus for two-dimensional capillary electrophoresis for automated mapping and sequencing of carbohydrates; provides efficient transfer of selected peaks between capillaries.

EP 447288 Amperometric detection cell to test electroactive materials in solution; has solid state palladium electrodes that detect amino acids and carbohydrates with reference electrode compensating gradient shifts. The improved cell is also useful in liquid chromatographic separations.

EP 439222 Water-soluble reagent and probe with a nonimmunoreactive protein or carbohydrate covalently attached; useful for detecting, capturing, and isolating a target nucleic acid acid. It can be used for the identification and diagnosis of human genetic disorders.

WO 9014421 New enzyme with PNGase F activity and free from contamination by Endo F; useful for the production of a carbohydrate, protein, or polypeptide sample free from Endo F products of the glycoprotein or glycopeptide.

EP 305870 Production of immunoproximity catalysts by forming antibodycatalytic group complexes using hapten corresponding to transition state complex.

$\begin{array}{lllc}\text { Assignee } & \text { Author } & \text { Date } & \text { Status }^{*} \\ \begin{array}{llll}\text { SEQ Ltd. } \\ \text { (Princeton, NJ) }\end{array} & \text { Ulmer KM } & 12 / 12 / 96 & \text { A }\end{array}$

PerSeptive BioSystems

Patterson $\mathrm{DH}$,

$11 / 21 / 96$

A (Cambridge, MA) Tarr GE

lowa State Univ.

Research

Foundation

(Ames, IA)

Beckman Instruments (Fullerton, CA)

IBM (Armonk, NY)

Perkin-Elmer

(Norwalk, CT)

ESA Inc.

(Chelmsford, MA)

Clinical Diagnostic Systems; Eastman Kodak (Rochester, NY);

Johnson \& Johnson

Clinical Diagnostics;

Warren $\mathrm{HC}$

Genzyme Corp. (Cambridge, MA)

Kollmorgen Corp. (Waltham, MA); Kim PS; Kallenbach NR IGEN Inc. (Rockville, MD)
Chang $\mathrm{H}$, Fung

$11 / 21 / 96$ EN, LiQ, Lu X, Yeung ES

Chen FA,

$10 / 29 / 96$

A

Evangelista RA Liu M

Wickramasinghe HK, Zenhausern F

9/18/96

A2

King MM,

Hoff LB, Khan

$\mathrm{SH}, \mathrm{O}$ 'Neill RA

$12 / 14 / 95$

A1

Bowers ML Buttaro DW

Krebs MW

9/18/91

$7 / 31 / 91$

Warren $\mathrm{HC}$

Barsomian GD, $\quad 11 / 29 / 90$ Johnson TL,

Rasmussen JR, Johnsson TL

Kim PS, $3 / 9 / 89$ 